\title{
Fatty Acid Composition of Ruditapes decussatus Spat Fed on Different Microalgae Diets
}

M. Albentosa, ${ }^{1}$ U. Labarta, ${ }^{2}$ M . J. Fernández-Reiriz ${ }^{2}$ and A. Perez-Camacho ${ }^{1}$

${ }^{1}$ INSTITUTO E SPAÑOL DE OCEANOGRAFIA, CENTRO COSTERO DE LA CORUÑA, LA CORUÑA, SPAIN AND ${ }^{2}$ INSTITUTO DE INVESTIGACIONES MARINAS, CSIC, VIGO, SPAIN

Address reprint requests to: M. Albentosa, Instituto Español de Oceanografia, Centro Costero de La Coruña, Apdo. 130, 15001 La Coruña, Spain.

ABSTRACT. The fatty acid composition of the Ruditapes decussatus spat fed on three different microalgal diets during 4 weeks was determined. The fatty acid pattern of each diet was also analysed. The diets used were Isochrysis galbana, clone T-ISO,

Tetraselmis suecica, and Phaeodactylum tricornutum. The fatty acid composition of the spat was usually well correlated with that of the diet supplied. Major differences among spat cultures were found in 14:0, 16:0, 16:1n-9, 16:1n-7, 18:1n-9, 18:2n-6, 18:3n-3, 18:4n-3, 20:5n-3, 22:5n-6 and 22:6n-3 fatty acids. These differences were correlated with the particular fatty acid content of each diet supplied. It has been shown that R. decussatus spat have a very low capacity to elongate and desaturate linolenic acid to n-3 PUFA, so when $20: 5 n-3$ or 22:6n-3 were not present in the diet, they were also absent, at least in measurable amounts, in the clams. The absence of any of the "essential" fatty acids, $20: 5 n-3$ in T-IS0 or 22:6n-3 in Tetraselmis, did not limit spat growth, so their role as "essential" fatty acids might be a matter for discussion. Finally, the nutritive value of each diet was discussed in terms of its fatty acid composition.

KEY WORDS. Fatty acids, microalgae diets, clam spat

\section{INTRODUCTION}

Lipids of marine animals have a high degree of unsaturation in their fatty acids, which is related to membrane fluidity at low temperatures (26). Polyunsaturated fatty acids (PUFA) are essential as they can not be synthesized "de novo." Some n-3 fatty acids, 
such as linolenic acid (18:3n-3), eicosapentanoic acid (20:5n-3) and docosahexanoic acid (22:6n-3), are very abundant in marine lipids $(1,27,9)$. The fatty acid composition of different bivalves species has been previously reported (see 34,35 for Crassostrea virginica and Ostrea edulis; 6 for Chlamys islandica; 7 for Tapes decussatus and T. Philippinarum; 19 for Myth edulis; and 4 for Venerupis pullastra). These studies have been focussed mostly on adults, and only a few of them have included larval or spat stages $(32,10,23,15$ on larvae of various oyster spp.; and 20 or 4 on small size spat).

The nutritive value of microalgal diets for molluscs seems to depend upon the presence of essential fatty acids. Trider and Castell (29) showed that n-3 fatty acids were preferentially required over $n-6$ fatty acids by C. virginica. The growth rate of C. gigas spat fed on diets deficient in C20 and C22 highly unsaturated fatty acids can be considerably increased if these fatty acids are additionally supplied within microcapsules (20). Elongation and desaturation activities of fatty acids were not high enough to sustain optimal growth rates in juvenile oysters (31). Thus, these authors pointed out that highly unsaturated fatty acids, such as $20: 5 n-3$ or $22: 6 n-3$, must be supplied in the diet. Elongation and desaturation of linolenic acid to n-3 PUFA were also highly limited in the V. pullastra clam spat, so when n-3 PUFAs were not present in the diet, they were not found in the spat (4).

This present work aimed to study the fatty acid composition of the clam spat, Ruditapes decussatus, and how the fatty acid profile of the diet had influence on that of the clams. Three microalgal diets with a different fatty acid composition were used: Isochrysis galbana (clone T-ISO), Tetraselmis suecica and Phaeodactylum tricornutum.

\section{MATERIALS AND METHODS}

Spat were obtained from a broodstock conditioned at the Instituto Español de Oceanografia (La Coruña, Spain). Spawning induction and larval cultures were realized according to Perez-Camacho et al. (24).

Determinations of size, live weight (LW), dry weight (DW) and organic matter content (considered as ash-free dry weight, AFDW) were done on a selected spat group. The clams used in this experiment had the following initial characteristics: $769 \pm 93$ pm of 
size, $0.151 \pm 0.003 \mathrm{mg}$ live weight ind ${ }^{-1}, 0.084 \pm 0.001 \mathrm{mg}$ dry weight ind $^{-1}$, and $14.50 \pm$ $0.01 \%$ of the dry weight was organic matter content.

The spat cultures were carried out in 61 plastic beakers. Clams were laid on the bottom of the beakers and a slight stream of air was applied to minimize the sedimentation rate of microalgae. Cultures were grown under isothermal conditions at $20 \pm 1{ }^{\circ} \mathrm{C}$ during 4 weeks. Sea water passed through 1 pm filters and sterilised with U.V. was used as culture water and changed daily. Spat growth, measured as live weight, was monitored weekly by weighing the total biomass after drying onto absorbent paper (10 $\mathrm{min})$ at room temperature. Live weight, dry weight and organic matter content were also determined after 4 weeks. Dry weight and organic matter content were determined after $24 \mathrm{hr}$ at either $80^{\circ} \mathrm{C}$ or $45 \mathrm{O}^{\circ} \mathrm{C}$, respectively.

The diets used were lsochrysis galbana (T-ISO), Tetraselmis suecica and Phaeodactylum tricornutum. The sedimentation rate of each diet was determined by adding it to a culture without clams. The experiments were carried out in triplicate for each diet. The microalgal diets were cultured in 61 glass bottles under isothermal conditions at $18^{\circ} \mathrm{C}$, and a continuous illumination of 9900 lux. Salinity was kept constant at $33 \mathrm{ppm}$. The culture medium used was that described by Walne (33). Microalgae were harvested from the early stationary phase of growth and supplied as food. The daily food ration, expressed as microalgal organic weight, was $2 \%$ of the spat live weight. The daily biomass increase resulting from spat growth was taken into account to maintain a constant food ration.

Samples from each diet were collected, centrifuged and then washed in $0.5 \mathrm{M}$ ammonium formate. Subsequently, they were freeze-dried and stored at $-30^{\circ} \mathrm{C}$ until required for analyses of fatty acid composition.

Lipids were firstly extracted with chloroform and methanol (1:2), and after centrifuging at $3246 \mathrm{x} \mathrm{g}$, re-extracted from the precipitate with chloroform and methanol (2:1). Both supernatants were washed into a chloroform, methanol and water solution (8:4:3) according to Folch et al. (14). Solvents contained $0.05 \%$ butylated hydroxytoluene (BHT). The total lipid content was determined gravimetrically on a Sartorius MSP balance $( \pm 1 \mu \mathrm{g}$ ) by evaporating the solvent from $200 \mu 1$ of purified extract spread on 
aluminum plates heated at $60-80^{\circ} \mathrm{C}$. The purified extract was stored under nitrogen at $70^{\circ} \mathrm{C}$ until required for fatty acid analyses.

Fatty acids from total lipid were transesterified to methyl esters by using methanolic hydrogen chloride (8) and subsequently analysed by gas chromatography (GC). A gas chromatograph (Perkin Elmer 8500) fitted with a fused silica capillary column (Supelco SP-2330, $30 \mathrm{~m}$ length, $0.25 \mathrm{~mm}$ i.d.) was used. Nitrogen was used as carrier gas at 10 psi. The injector temperature was set at $275^{\circ} \mathrm{C}$ and the temperature of the column was increased from $140^{\circ} \mathrm{C}$ to $210^{\circ} \mathrm{C}$ at a rate of $1^{\circ} \mathrm{C} \mathrm{min}^{-1}$. Nonadecanoic acid was used as an internal standard, and a response factor was determined for each fatty acid for quantitative analysis. Fatty acids were identified by co-injection of the sample with fatty acid methyl esters standards and GC-MS (Hewlett Packard 5971 Mass Detector). Chemicals, solvents and fatty acid standards were supplied by E. Merck, Darmstadt, and Sigma Chemical Co.

The results of the fatty acid composition of the spat fed on each diet was analysed by ANOVA to establish statistical significances. The relative percentage of each fatty acid was the mean value of hundreds of individuals, so that a normal distribution was guaranteed. Variance homogeneity was tested by the Barlett's test. If this was not the case, the angular transformation on the relative percentages was applied. The StudentNewman-Keuls' test (37) was performed to do multiple comparisons among the different treatments. Correlation analyses between the fatty acid composition of the diet and that of the spat fed on it were also performed. The Statgraphics statistical package was used for the statistical analyses.

\section{RESULTS}

Fatty Acid Composition of the Diets

The fatty acid composition of each microalgal diet is shown in Table 1. The content of each fatty acid was expressed as both the percentage relative to the total fatty acid content, and as pg per mg dry weight. The total lipid contents of T-IS0 $(28.78 \%$ of the organic matter) and Phaeodactylum (25.25\%) were considerably higher than that of Tetraselmis (11.92\%). Phaeodactylum and Tetraselmis lipids had a higher fatty acid 
proportion, that is, $85.49 \%$ and $66.63 \%$, respectively, than T-IS0 lipids, with $52.43 \%$. Nonetheless, in absolute values, the fatty acid content of T-IS0 (148.84 $\mu \mathrm{g})$ was higher than that of Tetraselmis $(74.36 \mathrm{pg})$ as a result of the lower lipid content of the latter microalga.

Saturated fatty acids were the major fatty acid group in all the diets, with values around $40 \%$ of the total fatty acid content. The highest proportion of polyunsaturated fatty acids was found in T-IS0 (33.30\%), followed by Tetraselmis (27.22\%). Phaeodactylum showed a lower PUFA content (17.07\%), although presenting the highest monosaturated fatty acid content (39.33\%). Fatty acids of the n-3 family were abundant in T-IS0 (25.69\%), as well as those of the n-9 family (19.01\%). Tetraselmis contained a higher proportion of $n-9(26.72 \%)$ than of $n-3$ fatty acids (20.55), although the latter were also abundant. The n-3 and n-9 fatty acid contents of Phaeodactylum were lower (12.88 and 5.38\%, respectively) than in the other microalgae and $n-7$ fatty acids were the major fatty acid family (33.96\%). Most n-3 fatty acids of Phaeodactylum were n-3 HUFA (highly unsaturated fatty acids), (nearly $80 \%$ ), especially 20:5n-3. Tetraselmis and TIS 0 contained a much lower n-3 PUFA proportion, (around 35\% of the n-3 fatty acid content). The n-3/n-6 ratio was very similar for all the diets, with a value around 3 .

The fatty acids predominant in T-IS0 and Tetraselmis were 16:0 and 18:1n-9. 16:1n-7 and 16:0 were the major fatty acids in Phaeodactylum, but 18:1n-9 was found in a low proportion. T-IS0 showed a high content of myristic acid 14:0, and so did Phaeodactylum, but not Tetraselmis, this microalgae was rich in linolenic acid (18:3n3), whereas T-IS0 had a lower content and Phaeodactylum hardly any of this fatty acid. Differences were also found in the linoleic acid content (18:2n-6). T-IS0 had a 18:4n-3 content much higher than the other diets. Differences were also recorded in the contents of some of the essential fatty acids, that is, 20:5n-3 and 22:6n-3. T-IS0 had a high $22: 6 n-3$ content (7.95\%), but very low amounts of 20:5n-3 (0.54\%). Tetraselmis did not have 22:6n-3, but 20:5n-3 was detected in relatively high amounts (5.63\%).

Phaeodactylum showed a high content of $20: 5 n-3$ (9.61\%) and a low proportion of $22: 6 n-3(0.74 \%)$.

Fatty Acid Composition of the Spat 
The fatty acid composition of the spat fed on each diet during 4 weeks is given in Table 2. The lipid and the fatty acid contents of R. decussatus spat were similar for any diet, with values around $20 \%$ of the organic matter and $30-40 \%$ of the total lipid content, respectively.

Saturated fatty acids were the most abundant fatty acid group in the clams, followed by the polyunsaturated (PUFA) and monounsaturated fatty acids. However, when Phaeodactylum was used as a diet, monounsaturated fatty acids were accumulated in a higher proportion than PUFAs. Significant differences $(p<0.01)$ were found in the contents of monounsaturated and polyunsaturated fatty acids as a result of the diet supplied. Monounsaturated fatty acid contents of Phaeodactylum and Tetraselmis were similar (ANOVA, $\mathrm{p}>0.05$ ), but significatively different from that of T-ISO. PUFA contents of T-IS0 and Tetraselmis were significatively different from that of Phaeodactylum. The more abundant fatty acid families in spat fed on T-IS0 or Tetraselmis were the n-3 and n-9 families, whereas the n-7 family was the most abundant in clams fed on Phaeodactylum. Most of the n-3 fatty acids of spat fed on TIS0 or Phaeodactylum were PUFAs, but a high proportion of n-3 acids was not accumulated when fed on Tetraselmis (nearly 40\%). The n-6, n-7 and n-9 fatty acid contents of clams fed on the different diets were significatively different. The $n-6$ and n7 fatty acid contents of spat fed on Tetraselmis or T-IS0 were different from that of spat fed on Phaeodactylum, which had a lower n-6 content and a higher n-7 content.

Differences among the n-9 fatty acid contents of each culture were also found.

The diets had an important and significative influence on the content of the following fatty acids: $14: 0,16: 1 n-9,16: 1 n-7,18: 1 n-9,18: 3 n-3,18: 4 n-3,20: 3 n-6,20: 5 n-3,22: 5 n-6$ and 22:6n-3. The content of 16:1n-7 was very low in clams fed on T-IS0 or Tetraselmis (1.78 and $1.56 \%$, respectively), but high when the diet was Phaeodactylum (14.48\%). TIS0 and Tetraselmis diets also gave rise to large amounts of 18:1n-9 in clams (11.81 and 17.88, respectively) but nor Phaeodactylum (4.59\%). Linolenic acid was abundant in spar fed on Tetraselmis, and 18:4n-3 in those fed on T-EGO. Phaeodactylum diets gave rise to low contents of both acids. Clams fed on T-IS0 contained a high 22:6n-3 content, but hardly had 20:5n-3, whereas if fed on Tetraselmis or Phaeodactylum had a high content of 20:5n-3, but low of 22:6n-3. 
Effects of the Diet on the Fatty Acid Composition of the Spat

The fatty acid composition of the spat reflects basically that of the diet. Thus, similar data were obtained for the different fatty acid groups of each diet and the seeds that were supplied to, as shown in Tables 1 and 2. Similar patterns also resulted among the different unsaturated fatty acid families. A large content of n-7 fatty acids in the Phaeodactylum diet was reflected in the clams fed on it. Total n-9 fatty acids were the major family in Tetraselmis and, so, in the clams fed on this diet. Therefore, the proportions of the different fatty acid groups and families of each diet determine similar proportions in the clams fed on them.

The main significant differences $(\mathrm{p}<0.01)$ found in the fatty acid content of the spat were well correlated with the proportions of those same fatty acids in the diets, i.e. 14:0, $16: 1 n-9,18: 1 n-9,16: 0,16: 1 n-7,18: 2 n-6,18: 3 n-3,18: 4 n-3,20: 5 n-3,22: 5 n-6$ and $22: 6 n-3$.

\section{DISCUSSION}

The fatty acid pattern of each microalgal diet was comparable to results previously reported (see 25,30, or 22 for Isochrysis; 30 or 13 for T. suecica; and (5) or 28 for P. tricornutum). The nutritive value of a microalga species depends, among other factors, upon its chemical composition (36). Dietary constituents have to provide not only the energy required for growth and sustenance, but also those compounds unable to be synthesized by the animal, such as essential fatty acids. Data obtained in the present study showed that nutritive value of each of the three microalgae used for R. decussatus spat is different.

In this sense, R. decussatus spat fed on Tetraselmis showed the highest growth and, then, if fed on T-ISO. On the contrary, the nutritive value of Phaeodactylum was lower for R. decussatus (Table 3, modified from 3). None of these diets has both fatty acids, although as was pointed out by Langdon and Waldock (20), any of them could satisfy the requirements for n-3 HUFAs. The requirement for essential fatty acids seems to be species-dependent. Tapes semidecussata and Mercenaria mercenaria required 22:6n-3, whereas Crassostrea spp. Showed a preferential requirement for 20:5n-3 (16). The 
absence of 22:6n-3 in Tetraselmis lipids might explain the lower nutritive value of this diet, in comparison with T-ISO, for the clam Venerupis pullastra (4). These authors also pointed out that a mixed diet, containing both microalgae, gave rise to a higher growth than a simple diet, partially due to the presence of both "essential" fatty acids in the mixed diet. According to these criteria, T-IS0 had a lower nutritive value than Tetraselmis for R. decussatus spat as a consequence of its higher requirement for 20:5n3. Nonetheless, Phaeodactylum, having a high 20:5n-3 content, was not suitable for R. decussatus. This points out that some other criteria, for example, ingestion rate, absorption efficiency, etc., should be used to explain the nutritive value of a diet (3).

The effect of the fatty acid composition of the diet on the fatty acid profile of bivalves has been studied previously. Some initial studies showed that the fatty acid composition of two oysters species did not depend on the diet $(34,35)$. However, the diet had a clear influence on the fatty acid pattern of Mesodesma mactroides according to De Moreno et al. (11). Similar results were found for larvae and spat of C. gigas (specially for the tryglyceride fraction) $(32,20)$ and for $\mathrm{V}$. pullastra spat fed on a number of diets $(4)$. Thus, these latter authors indicated that some fatty acids, such as n-3 HUFAs, were present in the spat only if they were also present in the diet. The present study has also shown that spat lipids reflect the fatty acid composition of the diet.

Clams fed on Phaeodactylum had a relatively high $18: 1 \mathrm{n}-7$ content (7\%). However, this fatty acid was contained in very small amounts in Phaeodactylum cells, so it must result from elongation of $16: 1 \mathrm{n}-7$ within the spat, since the latter is highly abundant in this $\operatorname{diet}(32.75 \%)$. Clams fed on any diet had 20:1n-9, but this fatty acid was not present in T-IS0 or Phaeodactylum diets, although it could have been formed by elongation of 18:1n-9. This is supported by the higher 20:1n-9 content in spat fed on T-IS0 than in those on Phaeodactylum, what seems to be related to the higher 18:1n-9 content in TIS0 than in Phaeodactylum. Although it was not detected in any of the diets, spat fed on Tetraselmis had a 20: 4n-6 content higher than the other clam cultures. This fatty acid could have resulted from desaturation of $20: 3 n-6$, which is more abundant in Tetraselmis. 
With regard to NMID, and though their function is not clearly discerned, it seems that their biosynthesis is regulated both functionally and physiologically. Actually, high amounts of these acids were observed in the membranes of sponges (21) and molluscs (2), which could indicate a functional and a structural role in the biological system. Klingensmith (18) working with clams clearly indicates a competitive incorporation between NMID and PUFAs, especially 20:5n-3 and 22:6n-3. Fang et al. (12) found that mussels from the Gulf of Mexico had a high NMID content, but not essential PUFA. In our study, however, we have found low levels of NMID.

The requirements of fish and crustacea for fatty acids is related to the bioconversion capacity to transform fatty acids from the diet in highly unsaturated fatty acids. The capacity to elongate and desaturate dietary $18: 3 n-3$ to $20: 5 n-3$ and 22:6n-3 is higher in freshwater fish than in marine fish or in crustacea (17). Radioactivity studies carried out on $\mathrm{C}$. gigus juveniles by marking dietary fatty acids with ${ }^{14} \mathrm{C}$ showed that they could elongate and desaturate n-3 fatty acids to produce n-3 HUFAs. However, this capacity was too low to maintain optimal growth rates (31). Similar results were found in C. virginica, with no detection of 20:5n-3 or 22:6n-3 resulting from ${ }^{14} \mathrm{C}$-marked $18: 3 n-3$ (9). Albentosa et al. (4) indicated that V. pullastra spat could not elongate and desaturate $18: 3 n-3$ to $20: 5 n-3$ and this latter to $22: 6 n-3$, as when these fatty acids were not present in the diet, they were not found in the spat either. Ruditapes decussatus spat seem not to be able to convert $18: 3 n-3$ to n-3 PUFA as a consequence of very low $\Delta 5$ and $\Delta 4$ desaturase activities. In this way, T-IS0 contained 18:3n-3 (3.23\%), but nearly lacks 20:5n-3 (0.54\%). Spat fed on T-IS0 did also have a low content of 20:5n-3 (1.48\%), reflecting the low content of this fatty acid in the diet rather than a low bioconversion capacity for 18:3n-3. Tetraselmis had a high content of 18:3n-3 (10.43\%) and of 20:5n$3(5.63 \%)$, but lacked $22: 6 n-3$, so clams fed on this diet showed a notable $20: 5 n-3$ content $(6.86 \%)$, but a small proportion of 22:6n-3 (1.04\%). Phaeodactylum had a high $20: 5 n-3$ content (9.61\%)) and a slight $22: 6 n-3$ content ( $0.74 \%)$, but almost no $18: 3 n-3$ (0.52\%). Spat fed on Phaeodactylum were rich in 20:5n-3 (12.54\%) and had a low content of $22: 6 n-3(2.65 \%)$. R. decussatus spat have a very limited ability to elongate and desaturate $20: 5 n-3$ to $22: 6 n-3$, so when this latter fatty acid was not present in the diet, it was only found in a very small proportion, if any, in spat lipids. Furthermore, when fatty acids such as 20:5n-3 in TIS0 or 22:6n-3 in Tetraselmis were not present, the growth of R. decussatus spat was not limited, so that their essentiality might be a matter 
for discussion. Consequently, criteria other than "essential" fatty acid content must be looked through in order to give an explanation to the different nutritive value of the microalgal diets tested (3).

We would like to thank C. Fernandez Pena for her helpful technical assistance in the algal and spat cultures and to J. L. Garrido, L. Nieto and B. Gonzalez in the biochemical analyses. This study was funded by CICYT-CSIC-IEO project I + D number MAR900821-C02-01.

\section{References}

1. Ackman, R. G. Fatty acid metabolism of bivalves. Proc. $2^{\text {nd }}$ Int. Conf. Aquaculture Nutr., Pruder, G. D.; Langdon, C.; Conklin, D., eds. World Mariculture Society, Spec. Publ. 2: 358-376; 1983.

2. Ackman, R. G.; Hooper, S. N. Nonmethylene interrupted fatty acids in lipids of shallow-wat (Litorina litorea and Lunatia triseriata) with the sand shrimp (Crungon septemspinosa). Comp. Biochem. Physiol. 64B: 153-165; 1973.

3. Albentosa, M. Evaluacion de dietas vivas e inertes para el cultivo de la semilla de Ruditapes decussatus mediante parámetros fisiologicos y bioquimicos. Doctoral Thesis, University of Santiago de Compostela, Spain; 1995.

4. Albentosa, M.; Labarta, U.; Perez-Camacho, A.; Fenandez-Reiriz, M. J. Fatty acid composition of Venerupis pullastra spat fed on different microalgae diets. Comp. Biochem. Physiol. 108A(4): 639-648; 1994.

5. Arao, T.; Kawaguchi, A.; Yamada, M. Positional distribution of fatty acids in lipids of the marine diatom, P. tricornutum. Phytochemistry 26:2573-2576; 1987.

6. Bell, M. V.; Sargent, J. R. Fatty acid analyses of phosphoglycerides from tissues of the clam Chlamys islandica (Muller) and the starfish Ctenodiscus crispatus (Retzius) from Balsfjorden, Northern Norway. J. Exp. Mar. Biol. Ecol. 87: 31-40; 1985.

7. Beninger, P. G.; Stephan, G. Seasonal variations in the fatty acids of the triacylglycerols and phospholipids of two populations of adult clam (Tapes decussatus L. and T. philippinarum) reared in a common habitat. Comp. Biochem. Physiol. 81B(3): 591-601; 1985.

8. Christie, W. W. Lipid analysis. Oxford: Pergamon Press; 1982: 52-53. 
9. Chu, F. E.; Greaves, J. Metabolism of palmitic, linoleic, and linolenic acids in adult oysters, Crassostrea virginica. Mar. Biol. 110: 229-236; 1991.

10. Chu, F. E.; Webb, K. L. Polyunsaturated fatty acids and neutral lipids in developing larvae of the oyster, Crassostrea virginica. Lipids, 19(11): 815-820; 1984.

11. DeMoreno, J. E. A.; Moreno, V. J.; Brenner, R. R. Lipid metabolism of the yellow clam, Mesodesma mactroides: 1. Composition of the lipids. Lipids 11: 334-340; 1976.

12. Fang, J.; Comet, P. A.; Brooks, J. M.; Wade, T. L. Nonmethylene-interrupted fatty acids of hydrocarbon seep mussels: occurrence and significance. Comp. Biochem. Physiol. 104B: 287-291; 1993.

13. Fenandez-Reiriz, M. J.; Perez-Camacho, A.; Ferreiro, M. J.; Blanco, J.; Planas, M.; Cameos, M. J.; Labarta, U. Biomass production and variation in the biochemical profile (total protein, carbohydrates, RNA, lipids and fatty acids) of 7 species of marine microalgae. Aquaculture 83: 17-37; 1989.

14. Folch, J.; Lees, M.; Sloane-Stanley, G. G. A simple method for the isolation and purification of total lipids from animal tissues. J. Biol. Chem. 226: 497; 1957.

15. Helm, M. M.; Holland, D. L.; Utting, S. D.; East, J. Fatty acid composition of early nonfeeding larvae of the European flat oyster, Ostrea edulis. J. Mar. Biol. Ass. U.K. 71: 691-705; 1991.

16. Helm, M. M.; Laing, I. Preliminary observations on the nutritional value of 'Tahiti Isochrysis' to bivalve larvae. Aquaculture 62: 281-208; 1987.

17. Kanazawa, A.; Teshima, S.; Ono, K. Relationship between essential fatty acid requirements of aquatic animals and the capacity for bioconversion of linolenic acid to highly unsaturated fatty acids. Comp. Biochem. Physiol. 63B: 295-298; 1979.

18. Klingensmith, J. S. Distribution of methylene and nonmethylene-interrupted dienoic fatty acids in polar lipids and triacylglycerols of selected tissues of the hardshell clam (Mercenaria mercenaria). Lipids 17: 976-981; 1982.

19. Kluytmans, J. H.; Boot, J. H.; Oudejans, R. C. H. M.; Zandee, D. I. Fatty acid synthesis in relation to gametogenesis in the mussel Mytilus edulis L. Comp. Biochem. Physiol. 81B(4): 959-963; 1985.

20. Langdon, C. J.; Waldock, M. J. The effect of algal and artificial diets on the growth and fatty acid composition of Crassostrea gigas spat. J. Mar. Biol. Ass. U.K. 61:431$448 ; 1981$. 
21. Morales, P. W.; Lichfield, C. Unusual C24, C25, C26 and C27 polyunsaturated fatty acids of the marine sponge Microciona prolifera. Biochim. Biophys. Acta 431:206$216 ; 1986$.

22. Napolitano, G. E.; Ackman, R. G.; Ratnayake, W. M. N. Fatty acid composition of three cultured algal species (Isochrysis galbana, Chaetoceros gracilis and Chaetoceros calcitrans) used as food for bivalve larvae. World Aquaculture Society 21(2): 122-130; 1990.

23. Napolitano, G. E.; Ratnayake, W. M. N.; Ackman, R. G. Fatty acid components of larval Ostrea edulis (L.): importance of triacylglycerols as a fatty acid reserve. Comp. Biochem. Physiol. 90B(4): 875-883; 1988.

24. Perez-Camacho, A.; Roman, G.; Torre Cervigon, M. Experiencias en cultivos de larvas de tres especies de moluscos bivalvos: Venerupis pullastra (Montagu), Venerupis decussata (Linnaeus) y Ostrea edulis (Linnaeus). Boletin del Instituto Español de Oceanografia. Tomo III, 235:7-62; 1977.

25. Pillsbury, K. S. The relative food value and biochemical composition of five phytoplankton diets for queen conch, Strombus gigas (Linne) larvae. J. Exp. Mar. Biol. Ecol. 90: 221-231; 1985.

26. Sargent, J. R. The structure, metabolism and function of lipids in marine organisms. In: Malins, D. C.; Sargent, J. R., eds. Biochemistry and Biophysical Perspectives in Marine Biology, Vol. 3. London: Academic Press; 1978: 149-212.

27. Sargent, J.; Henderson, R. J.; Tocher, D. R. The Lipids. In: Halver, J. E., ed. Fish Nutrition. London: Academic Press; 1988.

28. Siron, R.; Giusti, G.; Berland, B. Changes in the fatty acid composition of Phaeodactylum tricornutum and Dunaliella tertiolecta during growth and under phosphorus deficiency. Mar. Ecol. Prog. Ser. 55: 95-100; 1989.

29. Trider, D. J.; Castell, J. D. Influence of neutral lipid on seasonal variation of total lipid in oysters, Crassostrea virginica. Proc. Nat. Shell. Assoc. 70: 112-118; 1980.

30. Volkman, J. K.; Jeffrey, S. W.; Nichols, P. D.; Rogers, G. I.; Garland, C. D. Fatty acid and lipid composition of 10 species of microalgae used in mariculture. J. Exp. Mar. Biol. Ecol. 128: 219-240; 1989.

31. Waldock, M. J.; Holland, D. L. Fatty acid metabolism in young oysters, Crassostrea gigas: polyunsaturated fatty acids. Lipids 19(5): 332-336; 1984.

32. Waldock, M. J.; Nascimento, I. A. The triacylglycerol composition of Crassostrea gigas larvae fed on different algal diets. Mar. Biol. Letters 1: 77-86; 1979. 
33. Walne, P. R. Experiments in the large-scale culture of the larvae of Ostrea edulis L. Fishery Investigations, Series II, Vol. XXV. London: Ministry of Agriculture, Fisheries and Food; 1966.

34. Watanabe, T.; Ackman, R. G. Effect of unicellular algal lipids on oyster lipids and their fatty acid compositions. Fish. Res. Board Can. Tech. Report 334:1972.

35. Watanabe, T.; Ackman, R. G. Lipids and fatty acids of the American (Crassostrea virginica) and European flat (Ostrea edulis) oysters from a common habitat, and after one feeding with Dicrateria inornata or Isochrysis galbana. J. Fish. Res. Board Can. 31: 403-409; 1974.

36. Webb, K. L.; Chu, F. E. Phytoplankton as a food source for bivalve larvae. Proc. 2nd Int. Conf. Aquaculture Nutr. Pruder, G. D.; Langdon, C.; Conklin, D., eds. World Mariculture Society, Spec. Publ. 2: 272-291; 1983.

37. Zar, J. H. Biostatistical analysis. McElroy, W. D.; Swanson, C. P., eds. London: Prentice-Hall, Inc.; 1974. 
TABLE 1. Fatty acid composition of the three microalgal diets tested as food for Ruditapes decussates spat: Isochrysis galbana (clone T-ISO), Tetraselmis suecica and Phaeodactylum tricornutum

\begin{tabular}{|c|c|c|c|c|c|c|}
\hline \multirow[b]{2}{*}{ Fatty acid } & \multicolumn{2}{|c|}{ I. galbana, T-IS0 } & \multicolumn{2}{|c|}{ T. suecica } & \multicolumn{2}{|c|}{ P. tricornutum } \\
\hline & $\%$ & $\mu \mathrm{g} / \mathrm{mgDW}$ & $\%$ & $\mu \mathrm{g} / \mathrm{mgDW}$ & $\%$ & $\mu \mathrm{g} / \mathrm{mgDW}$ \\
\hline $14: 0$ & 14.31 & 21.30 & 1.50 & 1.11 & 6.12 & 12.57 \\
\hline $15: 0$ & 0.91 & 1.35 & 0.92 & 0.68 & 0.71 & 1.46 \\
\hline $16: 0$ & 17.04 & 25.36 & 27.54 & 20.48 & 28.20 & 57.96 \\
\hline $16: 1 n-9$ & 1.42 & 2.11 & 2.40 & 1.78 & 0.66 & 1.35 \\
\hline $16: 1 n-7$ & 2.72 & 4.05 & 1.01 & 0.75 & 32.75 & 67.29 \\
\hline $16: 4 n-3$ & 0.16 & 0.24 & 0.07 & 0.05 & 0.21 & 0.42 \\
\hline $17: 0$ & 0.92 & 1.37 & 1.15 & 0.85 & 0.67 & 1.37 \\
\hline $17: 1 n-7$ & 0.34 & 0.51 & 0.53 & 0.40 & 0.66 & 1.35 \\
\hline $18: 0$ & 9.91 & 14.75 & 7.54 & 5.60 & 7.79 & 16.01 \\
\hline $18: \ln -9$ & 17.59 & 26.18 & 22.65 & 16.85 & 4.27 & 8.78 \\
\hline $18: 1 n-7$ & 1.12 & 1.67 & 5.67 & 4.22 & 0.55 & 1.14 \\
\hline $18: 2 n-6$ & 2.76 & 4.11 & 2.69 & 2.00 & 1.14 & 2.34 \\
\hline $18: 3 n-6$ & 0.24 & 0.36 & 0.28 & 0.21 & 0.25 & 0.52 \\
\hline $18: 3 n-3$ & 3.23 & 4.81 & 10.43 & 7.76 & 0.52 & 1.07 \\
\hline $18: 4 n-3$ & 11.68 & 17.39 & 3.51 & 2.61 & 1.40 & 2.87 \\
\hline $18: 5 n-3$ & 1.10 . & 1.64 & 0.41 & 0.31 & n.d. & n.d. \\
\hline $20: 0$ & 0.42 & 0.62 & 0.21 & 0.15 & 0.12 & 0.24 \\
\hline $20: 1 n-9$ & n.d & n.d. & 1.67 & 1.24 & n.d. & n.d. \\
\hline $20: 3 n-6$ & 2.34 & 3.49 & 3.11 & 2.31 & 2.08 & 4.27 \\
\hline $20: 4 n-6$ & 0.80 & 1.18 & 0.43 & 0.32 & 0.48 & 0.99 \\
\hline $20: 4 n-3$ & 0.77 & 1.14 & 0.50 & 0.37 & 0.40 & $0: 82$ \\
\hline $20: 5 n-3$ & 0.54 & 0.80 & 5.63 & 4.18 & 9.61 & 19.75 \\
\hline $22: 5 n-6$ & 1.47 & 2.19 & 0.16 & 0.12 & 0.24 & 0.50 \\
\hline $22: 5 n-3$ & 0.26 & 0.39 & n.d. & n.d. & n.d. & n.d. \\
\hline $22: 6 n-3$ & 7.95 & 11.83 & n.d. & n.d. & 0.74 & 1.51 \\
\hline $24: 1 n-9$ & n.d. & n.d. & n.d. & n.d. & 0.44 & 0.91 \\
\hline$\sum n-3$ & 25.69 & 38.24 & 20.55 & 15.28 & 12.88 & 26.44 \\
\hline$\sum n-6$ & 7.61 & 11.33 & 6.67 & 4.96 & 4.19 & 8.62 \\
\hline
\end{tabular}




\begin{tabular}{lllllll}
\hline$\sum \mathrm{n}-7$ & 4.18 & 6.23 & 7.21 & 5.37 & 33.96 & 69.78 \\
$\sum \mathrm{n}-9$ & 19.01 & 28.29 & 26.72 & 19.87 & 5.37 & 11.04 \\
$\sum \mathrm{n}-3 \mathrm{HUFA}$ & 8.75 & 13.02 & 5.63 & 4.18 & 10.35 & 21.26 \\
$\mathrm{n}-3 / \mathrm{n}-6$ & 3.38 & & 3.08 & & 3.07 & \\
$\sum$ Sat & 43.51 & 64.75 & 38.86 & 28.87 & 43.61 & 89.61 \\
$\sum$ Mono & 23.19 & 34.52 & 33.93 & 25.24 & 39.33 & 80.82 \\
$\sum$ PUFA & 33.30 & 49.57 & 27.22 & 20.24 & 17.07 & 35.06 \\
Total FA & $52.52 *$ & 148.84 & 66.62 & 74.35 & 85.49 & 205.49 \\
Lipids & $28.78 \dagger$ & 283.39 & 11.92 & 111.60 & 25.25 & 240.38 \\
\hline
\end{tabular}

*Total fatty acids (FA) are noted as the percentage of total lipids. $\dagger$ Lipids are expressed as the percentage of the ash-free dry weight (AFDW). Undetected fatty acids are noted as n.d.

Data are expressed as $\%$ of the total fatty acid content and as $\mu \mathrm{g}$ per mg dry weight. 
TABLE 2. Fatty acid composition of R. decussatus spat fed on Isochrysis galbana (clone T-SO), Tetraselmis suecica and Phaeodactylum tricornum

\begin{tabular}{lllllllll}
\hline & Initial & \multicolumn{3}{c}{ I. galbana T-IS0 } & \multicolumn{3}{c}{ P. tricornutum } \\
\cline { 2 - 8 } Fatty acid & $\%$ & $\mu \mathrm{g} / \mathrm{mgDW}^{-1}$ & $\%$ & $\mu \mathrm{g} / \mathrm{mgDW}^{-1}$ & $\%$ & $\mu \mathrm{g} / \mathrm{mgDW}^{-1}$ & $\%$ & $\mu \mathrm{g} / \mathrm{mgDW}^{-1}$ \\
\hline $14: 0$ & 3.44 & 0.48 & $5.44 \pm 0.63$ & $0.57 \pm 0.08$ & $1.10 \pm 0.22$ & $0.10 \pm 0.03$ & $2.63 \pm 0.29$ & $0.19 \pm 0.02$ \\
$15: 0$ & 0.87 & 0.12 & $0.72 \pm 0.23$ & $0.08 \pm 0.03$ & $0.51 \pm 0.14$ & $0.05 \pm 0.02$ & $0.50 \pm 0.05$ & $0.04 \pm 0.01$ \\
$16: 0$ & 20.91 & 2.91 & $19.28 \pm 0.17$ & $2.01 \pm 0.05$ & $23.82 \pm 0.31$ & $2.11 \pm 0.29$ & $21.55 \pm 0.76$ & $1.58 \pm 0.18$ \\
$16: 1 \mathrm{n}-9$ & 1.07 & 0.15 & $1.32 \pm 0.25$ & $0.14 \pm 0.03$ & $2.62 \pm 0.12$ & $0.23 \pm 0.04$ & $0.89 \pm 0.12$ & $0.07 \pm 0.01$ \\
$16: 1 \mathrm{n}-7$ & 1.15 & 0.16 & $1.78 \pm 0.06$ & $0.19 \pm 0.01$ & $1.56 \pm 1.09$ & $0.15 \pm 0.12$ & $14.48 \pm 0.72$ & $1.06 \pm 0.06$ \\
$16: 4 \mathrm{n}-3$ & 0.21 & 0.03 & $0.22 \pm 0.06$ & $0.03 \pm 0.01$ & $0.20 \pm 0.01$ & $0.02 \pm 0.00$ & $0.28 \pm 0.06$ & $0.02 \pm 0.01$ \\
$17: 0$ & 0.89 & 0.13 & $0.97 \pm 0.14$ & $0.10 \pm 0.02$ & $0.51 \pm 0.09$ & $0.05 \pm 0.02$ & $0.63 \pm 0.13$ & $0.05 \pm 0.01$ \\
& & & & & & & 0.01 \\
$17: 1 \mathrm{n}-9$ & 1.42 & 0.20 & $0.82 \pm 0.12$ & $0.09 \pm 0.01$ & $0.72 \pm 0.03$ & $0.07 \pm 0.01$ & $1.92 \pm 0.07$ & $0.14 \pm 0.01$ \\
$18: 0$ & 32.43 & 4.51 & $13.17 \pm 3.29$ & $1.37 \pm 0.34$ & $8.81 \pm 0.38$ & $0.78 \pm 0.10$ & $14.14 \pm 3.44$ & $1.05 \pm 0.33$ \\
$18: 1 \mathrm{n}-9$ & 8.97 & 1.25 & $11.81 \pm 0.83$ & $1.23 \pm 0.09$ & $17.88 \pm 0.85$ & $1.58 \pm 0.18$ & $4.59 \pm 0.82$ & $0.34 \pm 0.06$ \\
$18: 1 \mathrm{n}-7$ & 1.96 & 0.28 & $3.12 \pm 0.16$ & $0.33 \pm 0.02$ & $3.11 \pm 0.11$ & $0.28 \pm 0.05$ & $7.00 \pm 0.37$ & $0.51 \pm 0.03$ \\
$18: 2 \mathrm{n}-6$ & 1.53 & 0.22 & $1.96 \pm 0.06$ & $0.21 \pm 0.01$ & $1.56 \pm 0.09$ & $0.14 \pm 0.02$ & $1.07 \pm 0.10$ & $0.08 \pm 0.01$ \\
$18: 3 \mathrm{n}-4$ & 0.06 & 0.01 & $0.17 \pm 0.15$ & $0.02 \pm 0.02$ & $0.23 \pm 0.02$ & $0.02 \pm 0.01$ & $0.39 \pm 0.02$ & $0.03 \pm 0.01$ \\
$18: 3 \mathrm{n}-3$ & 2.53 & 0.35 & $2.93 \pm 0.46$ & $0.31 \pm 0.05$ & $7.90 \pm 0.43$ & $0.70 \pm 0.06$ & $0.62 \pm 0.11$ & $0.05 \pm 0.01$ \\
\hline
\end{tabular}




\begin{tabular}{|c|c|c|c|c|c|c|c|c|}
\hline $18: 4 n-3$ & 3.67 & 0.51 & $7.67 \pm 0.32$ & $0.80 \pm 0.05$ & $3.58 \pm 0.08$ & $0.32 \pm 0.04$ & $0.73 \pm 0.24$ & $0.06 \pm 0.02$ \\
\hline $20: 0$ & 0.75 & 0.11 & $0.33 \pm 0.06$ & $0.04 \pm 0.01$ & $0.28 \pm 0.03$ & $0.03 \pm 0.00$ & $0.49 \pm 0.07$ & $0.04 \pm 0.01$ \\
\hline $20: 1 n-11$ & 0.17 & 0.03 & $0.15 \pm 0.13$ & $0.02 \pm 0.02$ & $0.22 \pm 0.06$ & $0.02 \pm 0.01$ & $0.33 \pm 0.06$ & $0.03 \pm 0.01$ \\
\hline $20: 1 n-9$ & 1.51 & 0.21 & $2.67 \pm 0.10$ & $0.28 \pm 0.01$ & $3.57 \pm 0.14$ & $0.32 \pm 0.03$ & $0.77 \pm 0.10$ & $0.06 \pm 0.01$ \\
\hline $20: 1 n-7$ & 0.27 & 0.04 & $0.50 \pm 0.04$ & $0.05 \pm 0.01$ & $0.31 \pm 0.02$ & $0.03 \pm 0.01$ & $0.96 \pm 0.06$ & $0.07 \pm 0.01$ \\
\hline 20:2NMID1 & 0.40 & 0.06 & $0.57 \pm 0.08$ & $0.06 \pm 0.01$ & $1.42 \pm 0.10$ & $0.13 \pm 0.01$ & $0.53 \pm 0.40$ & $0.04 \pm 0.03$ \\
\hline 20:2NMID2 & 0.12 & 0.02 & $0.29 \pm 0.04$ & $0.03 \pm 0.01$ & $0.43 \pm 0.04$ & $0.04 \pm 0.01$ & $0.77 \pm 0.18$ & $0.06 \pm 0.02$ \\
\hline $20: 2 n-6$ & 0.69 & 0.10 & $1.25 \pm 0.04$ & $0.13 \pm 0.01$ & $1.04 \pm 0.03$ & $0.09 \pm 0.01$ & $1.01 \pm 0.13$ & $0.08 \pm 0.01$ \\
\hline $20: 3 n-6$ & 1.34 & 0.19 & $1.64 \pm 0.04$ & $0.17 \pm 0.01$ & $1.18 \pm 0.07$ & $0.11 \pm 0.02$ & $1.61 \pm 0.27$ & $0.12 \pm 0.02$ \\
\hline $20: 4 n-6$ & 0.88 & 0.13 & $1.33 \pm 0.29$ & $0.14 \pm 0.03$ & $3.11 \pm 0.20$ & $0.28 \pm 0.02$ & $0.89 \pm 0.30$ & $0.07 \pm 0.02$ \\
\hline $20: 4 n-3$ & 0.41 & 0.06 & $0.96 \pm 0.12$ & $0.10 \pm 0.02$ & $1.10 \pm 0.07$ & $0.10 \pm 0.02$ & $0.40 \pm 0.15$ & $0.03 \pm 0.01$ \\
\hline $20: 5 n-3$ & 1.66 & 0.23 & $1.48 \pm 0.71$ & $0.15 \pm 0.07$ & $6.86 \pm 0.05$ & $0.61 \pm 0.08$ & $12.54 \pm 0.27$ & $0.92 \pm 0.08$ \\
\hline $22: 1 n-11$ & 0.20 & 0.03 & $0.22 \pm 0.04$ & $0.03 \pm 0.01$ & $0.22 \pm 0.03$ & $0.02 \pm 0.00$ & $0.19 \pm 0.10$ & $0.02 \pm 0.01$ \\
\hline 22:2NMID1 & 1.59 & 0.22 & $1.59 \pm 0.16$ & $0.17 \pm 0.02$ & $2.28 \pm 0.05$ & $0.20 \pm 0.03$ & $1.18 \pm 0.07$ & $0.09 \pm 0.01$ \\
\hline 22:2NMID2 & 0.34 & 0.05 & $0.46 \pm 0.08$ & $0.05 \pm 0.01$ & $0.40 \pm 0.04$ & $0.04 \pm 0.01$ & $1.88 \pm 0.11$ & $0.14 \pm 0.02$ \\
\hline $22: 4 n-6$ & 1.57 & 0.22 & $0.55 \pm 0.18$ & $0.06 \pm 0.02$ & $0.48 \pm 0.56$ & $0.05 \pm 0.06$ & $0.25 \pm 0.03$ & $0.02 \pm 0.01$ \\
\hline $22: 5 n-6$ & 1.08 & 0.15 & $2.22 \pm 0.14$ & $0.23 \pm 0.02$ & $0.51 \pm 0.09$ & $0.05 \pm 0.01$ & $0.38 \pm 0.09$ & $0.03 \pm 0.01$ \\
\hline $22: 5 n-3$ & 0.31 & 0.05 & $0.27 \pm 0.24$ & $0.03 \pm 0.03$ & $0.58 \pm 0.44$ & $0.05 \pm 0.03$ & $0.75 \pm 0.21$ & $0.06 \pm 0.02$ \\
\hline $22: 6 n-3$ & 5.11 & 0.71 & $10.74 \pm 0.45$ & $1.12 \pm 0.08$ & $1.04 \pm 0.04$ & $0.09 \pm 0.01$ & $2.65 \pm 0.43$ & $0.20 \pm 0.04$ \\
\hline $24: 1 n-9$ & 0.51 & 0.07 & $1.38 \pm 0.67$ & $0.15 \pm 0.07$ & $0.86 \pm 0.16$ & $0.08 \pm 0.02$ & $1.03 \pm 0.48$ & $0.08 \pm 0.04$ \\
\hline
\end{tabular}




\begin{tabular}{lllllllll}
\hline$\sum \mathrm{n}-3$ & 13.90 & 1.94 & $24.27 \pm 1.42$ & $2.54 \pm 0.15$ & $21.26 \pm 0.97$ & $1.89 \pm 0.16$ & $17.97 \pm 1.07$ & $1.34 \pm 0.14$ \\
$\sum \mathrm{n}-6$ & 7.09 & 1.01 & $8.95 \pm 0.14$ & $0.94 \pm 0.02$ & $7.88 \pm 0.18$ & $0.72 \pm 0.11$ & $5.21 \pm 0.76$ & $0.40 \pm 0.06$ \\
$\sum \mathrm{n}-7$ & 3.38 & 0.48 & $5.40 \pm 0.21$ & $0.57 \pm 0.03$ & $4.98 \pm 1.19$ & $0.46 \pm 0.17$ & $22.44 \pm 1.11$ & $1.64 \pm 0.09$ \\
$\sum \mathrm{n}-9$ & 13.68 & 1.91 & $18.22 \pm 1.36$ & $1.92 \pm 0.13$ & $25.87 \pm 0.89$ & $2.30 \pm 0.26$ & $9.39 \pm 1.02$ & $0.71 \pm 0.11$ \\
$\sum \mathrm{n}-11$ & 0.17 & 0.03 & $0.15 \pm 0.13$ & $0.02 \pm 0.02$ & $0.22 \pm 0.06$ & $0.02 \pm 0.01$ & $0.33 \pm 0.06$ & $0.03 \pm 0.02$ \\
$\sum \mathrm{n}-3$ PUFA & 7.08 & 0.99 & $12.49 \pm 1.06$ & $1.30 \pm 0.13$ & $8.48 \pm 0.58$ & $0.75 \pm 0.11$ & $15.94 \pm 0.96$ & $1.18 \pm 0.13$ \\
$\mathrm{n}-3 / \mathrm{n}-6$ & 1.96 & & $2.71 \pm 0.12$ & & $2.70 \pm 0.16$ & & $3.45 \pm 0.29$ & \\
$\sum$ NMID & 2.45 & 0.35 & $2.91 \pm 0.24$ & $0.31 \pm 0.02$ & $4.53 \pm 0.07$ & $0.41 \pm 0.04$ & $4.36 \pm 0.17$ & $0.33 \pm 0.03$ \\
$\sum$ Sat & 59.29 & 8.26 & $39.91 \pm 3.56$ & $4.17 \pm 0.25$ & $35.03 \pm 0.45$ & $3.12 \pm 0.45$ & $39.94 \pm 3.74$ & $2.95 \pm 0.50$ \\
$\sum$ Mono & 17.23 & 2.42 & $23.77 \pm 1.63$ & $2.51 \pm 0.16$ & $31.07 \pm 0.61$ & $2.78 \pm 0.41$ & $32.16 \pm 1.63$ & $2.38 \pm 0.19$ \\
$\sum$ PUFA & 23.50 & 3.31 & $36.30 \pm 1.94$ & $3.81 \pm 0.20$ & $33.90 \pm 0.98$ & $3.04 \pm 0.31$ & $27.93 \pm 2.21$ & $2.10 \pm 0.24$ \\
Total FA & $51.47 *$ & 13.99 & $40.56 \pm 2.82$ & $10.49 \pm 0.25$ & $36.74 \pm 4.05$ & $8.94 \pm 1.16$ & $33.67 \pm 1.92$ & $7.43 \pm 0.76$ \\
Lipids & $18.74 \dagger$ & 27.18 & 20.03 & 25.86 & 16.84 & 24.33 & 17.01 & 22.07 \\
\hline
\end{tabular}

*Total fatty acids \% (FA) are noted as a percentage of total lipids and $\dagger$ lipids \% are expressed as percentage of the organic matter.

Data are expressed as $\%$ of the total fatty acid content and as $\mu \mathrm{g}$ per mg dry weight. Average values of the three replicates and $( \pm)$ standard deviations are shown. 
TABLE 3. Live and dry weights, organic contents (considered as ash-free dry weight, AFDW) and size of R. decussatus spat fed on three microalgal diets: I. galbana, clone TISO, T. suecica and P. tricornutum during 4 weeks

\begin{tabular}{lccll}
\hline & Live weight & Dry weight & Size \\
\cline { 2 - 3 } \cline { 5 - 5 } Diet & \multicolumn{2}{c}{$\mathrm{mg} /$ ind } & \% AFDW & $\mathrm{mm}$ \\
\hline I. galbana, T-IS0 & $0.883 \pm 0.070$ & $0.534 \pm 0.014$ & $13.8 \pm 1.55$ & $1.42 \pm 0.02$ \\
T. suecica & $1.102 \pm 0.048$ & $0.609 \pm 0.048$ & $14.5 \pm 0.29$ & $1.51 \pm 0.05$ \\
P. tricornutum & $0.664 \pm 0.028$ & $0.370 \pm 0.003$ & $12.9 \pm 1.57$ & $1.20 \pm 0.05$ \\
\hline
\end{tabular}

Data obtained from 3.

Average values of the three replicates and $( \pm)$ standard deviations are shown. 